\title{
Mesothelioma mortality in men: trends during 1977- 2001 and projections for 2002-2016 in Spain
}

\author{
S Pitarque, ${ }^{1}$ R Clèries, ${ }^{2} \mathrm{~J}$ M Martínez, ${ }^{1,3}$ G López-Abente, ${ }^{3,4}$ M Kogevinas, ${ }^{3,5,6}$ \\ F G Benavides ${ }^{1,3}$
}

\begin{abstract}
- Additional figure is published online only at http://oem.bmj. com/content/vol65/issue4

${ }^{1}$ Unitat de Recerca en Salut Laboral, Universitat Pompeu

Fabra, Barcelona, Spain;

${ }^{2}$ Institut Català d'Oncologia,

Barcelona, Spain; ${ }^{3}$ Centro de

Investigación Biomédica en red (CIBER) de Epidemiologia y

Salud Pública, Spain; ${ }^{4}$ Instituto de Salud Carlos III, Madrid,

Spain; ${ }^{5}$ Centre de Recerca en

Epidemiología Ambiental-IMIM

Barcelona, Spain; ${ }^{6}$ Medical

School, University of Crete,

Heraklion, Crete
\end{abstract}

Correspondence to:

Sívia Pitarque, Occupational

Health Research Unit,

Universitat Pompeu Fabra,

Barcelona, Spain; Silvia.

pitarque@upf.edu

Accepted 3 August 2007

Published Online First

21 September 2007

\section{ABSTRACT}

Objectives: To evaluate mesothelioma death trends in Spain and to predict the number of future cases of mesothelioma.

Methods: After descriptive analysis of mesothelioma mortality data, an age-period-cohort model was applied to estimate future mesothelioma deaths.

Results: From 1977 to 2001, 1928 men over 35 years of age died of mesothelioma in Spain. Projections indicate that 1321 men are expected to die from mesothelioma between 2007 and 2016.

Conclusion: It is expected that mesothelioma deaths will increase at least until 2016. Available data do not allow prediction of the year when mortality will start to decrease.

Exposure to asbestos is the main cause of mesothelioma. ${ }^{1}$ The number of mesothelioma deaths reflects past exposure to asbestos and can be used to make future projections. Increases in mesothelioma deaths in recent years have been reported in several countries and future projections indicate a continuation of this increase in mortality in the future even though use of asbestos has been banned in most industrialised countries. ${ }^{2-6}$

Spain was not an asbestos producing country, but around 800 companies used 2.6 million tonnes of asbestos between 1900 and 2000 (chrysotile was $90 \%$ of the total). ${ }^{7}$ Use was especially high between 1960 and the mid 1980s, reaching its peak in 1973 (113 000 tonnes). . Asbestos regulations were first introduced in 1984 and asbestos was banned in 2001; residual activities involving asbestos exposure were regulated in $2006 .^{\circ}$

An estimate of occupational exposure to asbestos in Spain indicates that 56600 workers were exposed to asbestos in the late 1990s, mainly in the construction industry.

The main aim of this study was to analyse trends in mesothelioma mortality and to predict the number of deaths due to mesothelioma in men in the future in Spain. This estimation may be useful for planning and supporting active medical surveillance programs that aim to increase awareness of asbestos exposure in Spain, encourage the discovery of unregistered formerly exposed workers, and identify and compensate for occupational diseases when necessary.

\section{METHODS}

Pleural cancer mortality and mesothelioma mortality are acknowledged indicators of exposure to asbestos. Tables giving the number of pleural neoplasm deaths (ICD-9: 163) for men and women between 1977 and 2001 have been provided by the Centro Nacional de Epidemiología ${ }^{10}$ arranged in five 5-year periods (1977-1981, 1982-1986, 19871991, 1992-1996 and 1997-2001) and nine 5-year age groups (35-39 to 75-79 years of age). To avoid strata without deaths, considering that mesothelioma with less than 20 years' latency ${ }^{11}$ is only rarely observed and assuming earliest entry to industrial work at age 15, the lowest age group we used was 35-39 years of age. Mesothelioma deaths in people aged 80 or older were excluded from the analysis due to the lack of accuracy in determining the cause of death. ${ }^{12}$

The calendar periods and the age groups examined involved 13 overlapping birth cohorts, defined by their central year of birth beginning in 1902 and ending in 1962. Data were analysed by log-linear Poisson regression, assuming that the number of deaths follows a Poisson distribution. We fitted the complete age-period-cohort model to the age-specific death rates, investigating model fitting through the Akaike information criterion (AIC) and the deviance (DEV). The assessment and graphical representation of age, period and cohort effects was performed through a sequential fitting of an age-cohort model and an age-period model with the fitted rates of the age-cohort model as an offset, taking the 1932 birth cohort as the reference cohort.

These effects have been assessed by means of their $95 \%$ confidence intervals. The annual per cent change in rates has been estimated through an agedrift model. The age-drift model is a submodel of both the age-period and age-cohort models. It should be noted that when we have a constant annual change in rates, it makes no sense to attribute this to either period or cohort. Whatever the true mechanism behind such a regular temporal variation in rates, the observed rates would be the same. ${ }^{13}$

A Bayesian age-period-cohort model with an autoregressive structure for each of the parameters $^{14}$ has been used to project mesothelioma mortality in Spain for the periods 2002-2006, 2007-2011 and 2012-2016. Mesothelioma projections in Spain were estimated based on mesothelioma mortality data in men from 1977 to 2001 Mortality projections in women are not shown because we have not observed any changes in the rates for the analysed period, and mesothelioma in women is more commonly related to household and neighbourhood exposures. For that reason, it cannot be legally recognised as an occupational disease (data available on request). 


\section{RESULTS}

From 1977 to 2001, 2929 people over 35 years of age died of mesothelioma in Spain: 1928 were men (65.8\%) and 1001 women $(34.2 \%)$, with a male to female ratio of $\sim 2$. The crude rate rose from 0.73 per 100000 (270 cases) in 1977-1981 to 1.13 per 100000 (520 cases) in 1997-2001, while rates in women remained stable or even decreased, from 0.50 (207 cases) in 1977-1981 to 0.34 (169 cases) in 1997-2001. Death numbers and mortality rates per 100000 men-years by birth cohort and age at death are shown in table 1.

Older age groups show the highest mortality rates by birth cohort (fig 1A, left panel) and by period of death (fig 1A, right panel). Mortality rose dramatically in cohorts after 1930. A statistically significant increase in death rates by $1.96 \%$ per year was detected by means of the age-drift model. The age-cohort model (AIC $=301.2$ and DEV $=23.9)$ did not differ statistically from the age-period-cohort model (AIC $=305.8$ and $\mathrm{DEV}=22.5)$ in terms of model fitting. For that reason, cohort effect was considered more important than period effect (see supplemental fig 2). Graphical representation of age-periodcohort effects (graphic not shown) depicted an exponential rise in mortality rates after the age of 50 (age effect), an increase for cohorts between 1937 and 1947 (cohort effect), and a flat period effect.

Projections indicate that the numbers of deaths among men due to mesothelioma will increase until 2016 (fig 1B). Specifically, it can be expected that 636 deaths will occur between 2007 and 2011 (95\% CI 499 to 656) and 685 deaths between 2012 and 2016 (95\% CI 497 to 960).

Table 1 Age-specific mesothelioma death numbers and rates (in italicised numbers) by birth cohort and age at death, Spain 1977-2001

\begin{tabular}{|c|c|c|c|c|c|c|c|c|c|}
\hline \multirow{2}{*}{$\begin{array}{l}\text { Birth } \\
\text { cohort }\end{array}$} & \multicolumn{9}{|c|}{ Age group } \\
\hline & \multicolumn{2}{|c|}{$35-3940-44$} & $45-49$ & $50-54$ & $55-59$ & $60-64$ & $65-69$ & $70-74$ & $75-79$ \\
\hline \multirow[t]{2}{*}{1902} & & & & & & & & & 35 \\
\hline & & & & & & & & & 2.23 \\
\hline \multirow[t]{2}{*}{1907} & & & & & & & & 59 & 66 \\
\hline & & & & & & & & 2.43 & 3.56 \\
\hline \multirow[t]{2}{*}{1912} & & & & & & & 48 & 48 & 48 \\
\hline & & & & & & & 1.57 & 1.82 & 2.37 \\
\hline \multirow[t]{2}{*}{1917} & & & & & & 41 & 54 & 66 & 70 \\
\hline & & & & & & 1.17 & 1.71 & 2.44 & 3.32 \\
\hline \multirow[t]{2}{*}{1922} & & & & & 38 & 48 & 73 & 92 & 97 \\
\hline & & & & & 0.82 & 1.11 & 1.85 & 2.71 & 3.97 \\
\hline \multirow[t]{2}{*}{1927} & & & & 26 & 42 & 70 & 78 & 114 & \\
\hline & & & & 0.49 & 0.82 & 1.44 & 1.75 & 3.04 & \\
\hline \multirow[t]{2}{*}{1932} & & & 15 & 26 & 50 & 85 & 102 & & \\
\hline & & & 0.26 & 0.46 & 0.92 & 1.85 & 2.17 & & \\
\hline \multirow[t]{2}{*}{1937} & & 3 & 10 & 32 & 51 & 66 & & & \\
\hline & & 0.06 & 0.19 & 0.83 & 1.04 & 1.32 & & & \\
\hline \multirow[t]{2}{*}{1942} & 5 & 9 & 13 & 41 & 66 & & & & \\
\hline & 0.09 & 0.17 & 0.25 & 0.81 & 1.40 & & & & \\
\hline \multirow[t]{2}{*}{1947} & 3 & 11 & 34 & 33 & & & & & \\
\hline & 0.05 & 0.18 & 0.58 & 0.59 & & & & & \\
\hline \multirow[t]{2}{*}{1952} & 5 & 6 & 24 & & & & & & \\
\hline & 0.08 & 0.09 & 0.39 & & & & & & \\
\hline \multirow[t]{2}{*}{1957} & 7 & 14 & & & & & & & \\
\hline & 0.11 & 0.21 & & & & & & & \\
\hline \multirow[t]{2}{*}{1962} & 4 & & & & & & & & \\
\hline & 0.05 & & & & & & & & \\
\hline
\end{tabular}

\section{DISCUSSION}

Mesothelioma deaths for men increased from 1977 to 2001, and projections indicate a continuous increase until 2016. We estimated that 1321 deaths from mesothelioma will occur between 2007 and 2016. This is the first prediction of mesothelioma deaths in Spain.

Analyses of mortality data in men by birth cohort showed a clear age effect with an exponential increase. Moreover, the youngest birth cohorts from each age group showed an increasing trend that suggested a birth cohort effect. We did not observe such a pattern when we analysed the same data by period of death. Results support a non-existing period effect since deviation from linearity has not been detected for this effect.

This predicted death increase in Spain is low compared to other countries. For example, a peak of 3300 annual deaths has been suggested for around the year 2020 in the UK, ${ }^{2}$ and in Italy, which produced asbestos, 800 annual deaths have been estimated for 2012-2024. ${ }^{4}$ The highest number of deaths have been forecast for Japan, with 101400 deaths for the period 2000-2039. ${ }^{6}$ Large amounts of asbestos were used in Japan during the 1970s (350 000 tonnes per year) and it was the last country to introduce preventive measures in 2003. The low numbers predicted for Spain are due to the considerably smaller amount of asbestos used compared to other countries. ${ }^{7}$ However, as Spain was one of the last countries to introduce regulations (in 1984) and did not ban asbestos until 2001, this will prolong the increase in mortality over time.

In making the predictions for Spain, we did not take into account possible changes in asbestos exposure during the period. For instance, in the $\mathrm{UK}^{2}$ it was assumed that people born after 1953 had a 50\% lower risk of mesothelioma death than people born before that date. The prediction in France established a similar cut-off at 1964 because asbestos consumption started later in France than in the UK. ${ }^{5}$ In the Spanish projection, no reduced risk assumptions were adopted because asbestos regulations in Spain only began in 1984, and chrysotile was not banned until 2001. Therefore, given a latency period of 3040 years, ${ }^{11}$ these regulations will not effect mortality until approximately 2014-2024. However, projections based on these assumptions have to be interpreted carefully because there are many factors which might influence exposure (eg, legal measures, the amount and type of asbestos used, etc) and therefore modify mortality trends. In the Netherlands, where over 950 annual mesothelioma deaths among men were initially predicted around the year 2025, a recent updated study has reduced this number to 490 in 2017 and 338 in 2028. ${ }^{15}$

Changes in death classification criteria may influence the evaluation of mortality trends. Some projections multiplied the number of deaths coded as ICD-9: 163 (pleural cancer) to provide a comparable classification with the more specific code used in ICD-10 (C45.0 pleural mesothelioma). For example, a factor of 0.797 was used in France to estimate pleural mesothelioma cases from the total number of pleural cancer deaths ${ }^{5}$ and a factor of 0.73 was used in Italy. ${ }^{4}$ The ICD-10 classification was introduced in 1999 in Spain, but for reasons of consistency we used deaths coded by ICD-9 for the entire study period. In Spain, there are no studies that would allow us estimate the number of pleural mesothelioma deaths from the total number of pleural cancer cases.

We focused this analysis on mesothelioma in men, because asbestos exposure has been mainly occupational. ${ }^{16}$ Nevertheless, a high but uncertain number of cases, mainly in women, are caused by environmental exposure to asbestos (living beside 
Figure 1 (A) Male mesothelioma mortality rates by birth cohort and period of death. (B) Mesothelioma death projections for men based on 1977-2001 mortality data. Solid line represents numbers of cases observed for 19772001 and broken lines show the 95\% confidence intervals for projected deaths during 2002-2016.
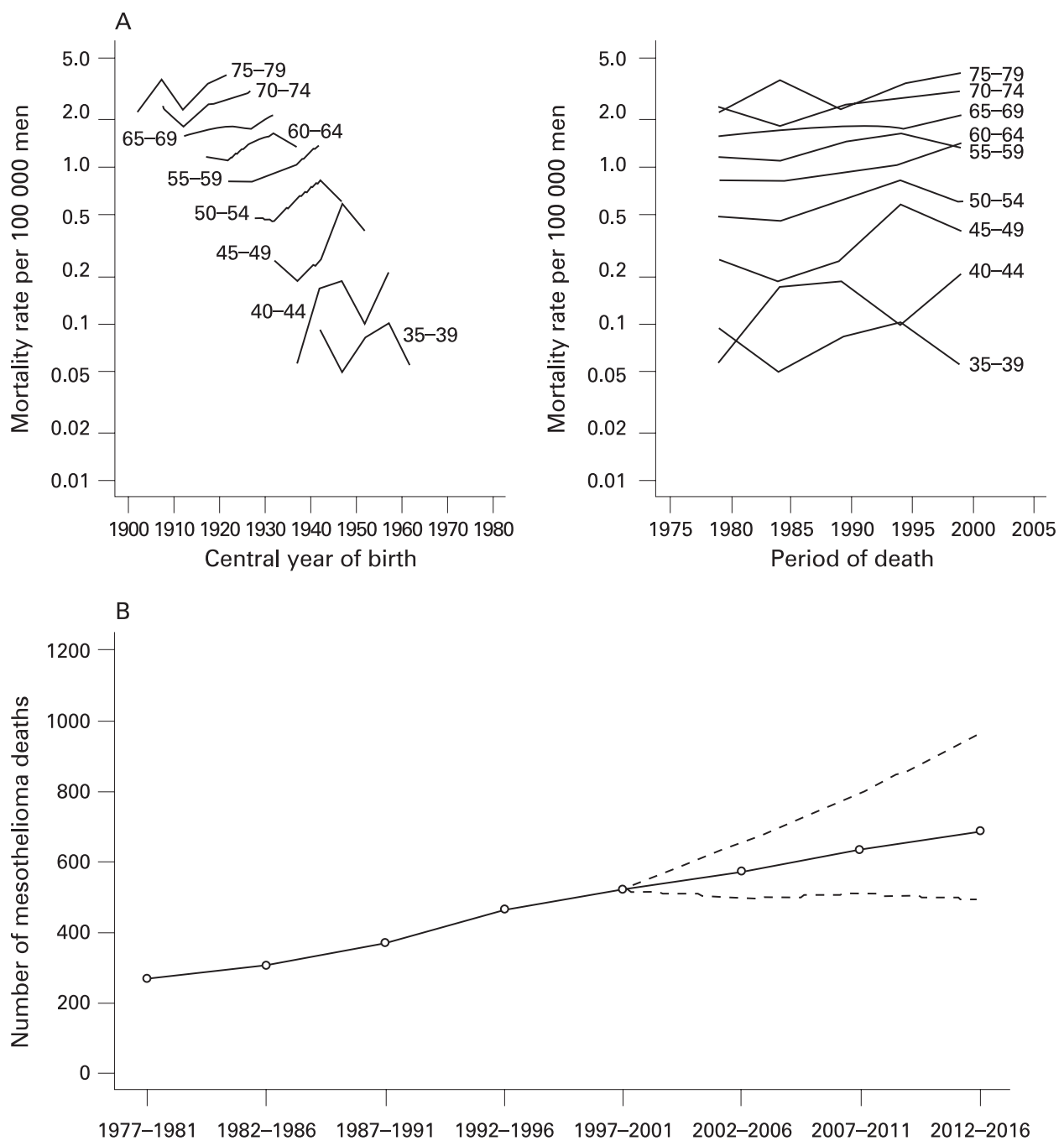

asbestos cement plants, contact with asbestos workers, etc). Agudo et al estimated that $38 \%$ of mesotheliomas can be attributed to environmental exposure. ${ }^{17}$

These projections show a constant increase in the number of deaths due to mesothelioma in men over the next decade. This is an expected consequence of past occupational exposure to asbestos. These figures differ widely from the number of cases of lung cancer related to asbestos exposure recognised as occupational diseases in Spain, that is, six cases in 2003 and

\section{Main messages}

- Mesothelioma deaths in men are expected to increase at least until 2016.

- Preventive and legal measures might start taking effect in 2014-2024.

\section{Policy implication}

The number of estimated cases of mesothelioma indicates that a medical surveillance program for asbestos exposed workers should be initiated. five in $2004 .{ }^{18}$ These results indicate that an active medical surveillance program based on all workers with a history of asbestos exposure should be initiated in order to recognise and compensate them for their occupational diseases. Such a program would have to guarantee access to the most sophisticated diagnostic tests to ensure its success.

Competing interests: None.

\section{REFERENCES}

1. IARC. Monographs on the evaluation of carcinogenic risk to man. Vol 14. Asbestos. Lyon: IARC, 1977:1-106.

2. Peto J, Hodgson JT, Matthews JE, et al. Continuing increase in mesothelioma mortality in Britain. Lancet 1995;345:535-9.

3. La Vecchia C, Decarli A, Peto J, et al. An age, period and cohort analysis of pleural cancer mortality in Europe. Eur J Cancer Prev 2000;9:179-84.

4. Marinaccio A, Montanaro F, Mastrantonio M, et al. Predictions of mortality from pleural mesothelioma in Italy: a model based on asbestos consumption figures supports results from age-period-cohort models. In J Cancer 2005;115:142-7.

5. Banaei A, Auvert B, Goldberg M, et al. Future trends in mortality of French men from mesothelioma. Occup Environ Med 2000;57:488-94.

6. Murayama T, Takahashi K, Natori Y, et al. Estimation of future mortality from pleural malignant mesothelioma in Japan based on an age-cohort model. Am J Ind Med 2006;49:1-7.

7. Cárcoba A. El amianto en España. Madrid: Ediciones GPS, 2000.

8. Real Decreto 396/2006, de 31 de marzo, por el que se establecen las disposiciones mínimas de seguridad y salud aplicables a los trabajos con riesgo de exposición a amianto. BOE núm. 86 de 11 de abril. 
9. Kogevinas M, Maqueda J, De la Orden V, et al. Exposición a carcinógenos laborales en España: aplicación de la base de datos CAREX. Arch Prev Riesgos Labor 2000;3(4):153-9.

10. Instituto de Salud Carlos III. Mortalidad. España y comunidades autónomas.Available at http://www.isciii.es/htdocs/centros/epidemiologia/ mortalidad.jsp (accessed 7 January 2008).

11. Bianchi C, Giarelli L, Grandi G, et al. Latency periods in asbestos-related mesothelioma of the pleura. Eur J Cancer Prev 1997;6:162-6.

12. Jarvholm B, Englund A, Albin M. Pleural mesothelioma in Sweden: an analysis of the incidence according to the use of asbestos. Occup Environ Med 1999;56:110-13.

13. Clayton D, Schifflers E. Models for temporal variation in cancer rates. I: Age-period and age-cohort models. Stat Med 1987;6:449-67.
14. Bashir SA, Estève J. Projecting cancer incidence and mortality using Bayesian ageperiod-cohort models. J Epidemiol Biostat 2001;6:287-96.

15. Segura 0, Burdorf A, Looman C. Update of predictions of mortality from pleural mesothelioma in the Netherlands. Occup Environ Med 2003;60:50-5.

16. Steenland K. Dying for work: the magnitude of US mortality from selected causes of death associated with occupation. Am J Ind Med 2003:43:461-82.

17. Agudo A, Gonzalez CA, Bleda MJ, et al. Occupation and risk of malignant pleural mesothelioma. A case-control study in Spain. Am J Ind Med 2000;37:159-68.

18. Kogevinas M, Rodriguez MM, Tardon A, et al. Cancer laboral en España. Madrid: ISTAS, 2006.

\section{Access the latest content chosen by our Editors}

BMJ Journals editors select an article from each issue to be made free online immediately on publication. Other material is free after 12 months to non-subscribers. Access the Editor's Choice from the home page-or expand your horizons and see what the other BMJ Journals editors have chosen by following the links on any BMJ Journal home page. 